\title{
Clinical factors of importance for outcome after lumbar disc herniation surgery: long-term follow-up
}

\author{
Katarina Silverplats $\cdot$ B. Lind $\cdot$ B. Zoëga $\cdot$ \\ K. Halldin $\cdot$ M. Gellerstedt $\cdot$ H. Brisby $\cdot$ \\ L. Rutberg
}

Received: 11 August 2009/Revised: 14 March 2010/ Accepted: 2 May 2010/Published online: 29 May 2010

(C) Springer-Verlag 2010

\begin{abstract}
Factors as age, sex, smoking, duration of leg pain, working status, type/level of disc herniation and psychosocial factors have been demonstrated to be of importance for short-term results after lumbar discectomy. There are few studies with long-term follow-up. In this prospective study of lumbar disc herniation patients undergoing surgery, the result was evaluated at 2 and 5-10 (mean 7.3) years after surgery. Predictive factors for satisfaction with treatment and objective outcome were investigated. Out of the included 171 patients undergoing lumbar discectomy, $154(90 \%)$ patients completed the 2-year follow-up and 140 (81\%) completed the long-term follow-up. Baseline data and questionnaires about leg- and back pain intensity (VAS), duration of leg pain, disability (Oswestry Disability Index), depression (Zung Depression Scale), sick leave and employment status were obtained preoperatively, at 2-year- and long-term follow-up. Primary outcome included patient satisfaction with treatment (at both time points) and assessment of an independent observer at the 2-year follow-up. Secondary outcomes at
\end{abstract}

\footnotetext{
K. Silverplats $(\bowtie) \cdot$ B. Lind $\cdot$ K. Halldin $\cdot$ H. Brisby Department of Orthopaedics, Sahlgrenska University Hospital, Göteborg University, 41345 Gothenburg, Sweden

e-mail: katarina.ronnberg@vgregion.se

B. Zoëga

Department of Orthopaedics, Landspitali University Hospital, Reykjavik, Iceland

M. Gellerstedt

Department of Orthopaedics, Trollhättan/Uddevalla University, Uddevalla, Sweden

L. Rutberg

Department of Neurology, Sahlgrenska University Hospital, Gothenburg, Sweden
}

2-year follow-up were improvement of leg and back pain, working capacity and the need for analgesics or sleeping pills. In about $70 \%$ of the patients excellent or good overall result was reported at both follow-ups, with subjective outcome measurements. The objective evaluation after 2 years was in agreement with this result. Time on sick leave was found to be a clinically important predictor of the primary outcomes, with a potential of changing the probability of a satisfactory outcome (both objective and subjective) from around 50\% (sick leave $>3$ months) to $80 \%$ (sick leave $<2$ months). Time on sick leave was also an important predictor for several of the secondary outcomes; e.g. working capacity and the need for analgesics.

Keywords Disc herniation · Surgery · Long-term follow-up · Clinical outcome $\cdot$ Predictive factor

\section{Introduction}

A majority of the patients suffering from sciatica caused by a lumbar disc herniation experience a positive natural history and respond well to nonsurgical treatment [1]. Lumbar disc herniation surgery is most commonly performed electively in patients where conservative therapies have failed to gain improvement of leg pain and disability [2]. Only in rare cases, acute surgery need to be performed, e.g. when a large disc herniation result in cauda equina syndrome.

Short-term results after surgical treatment of symptomatic lumbar disc herniation has been reported to have a high success rate (70-95\%), evaluated by validated outcome scores and patients satisfaction [3-6]. The long-term results after surgery have been found to have a lower success rate with about one-third of the patients reporting unfavourable results [7]. In the study by Weber et al. [8], no significant 
differences in clinical outcome between surgically and non-surgically treated patients were found 4 years after surgery. However, in more recent long-term follow-up studies, surgically treated patients demonstrated improved satisfaction with treatment and better leg pain relief compared with a conservative regime [2,9]. In these studies, no differences in clinical outcome (work status or disability) between surgically and conservatively treated patients were seen. The difference in success rate in different studies may be influenced by factors such as patient selection, different outcome variables and follow-up time.

To evaluate the outcome after a certain treatment, the patients' subjective satisfaction has lately been suggested to be as important as objective outcome instruments [5]. Furthermore, it is of importance to separate the surgical effects on back and leg pain in disc herniation patients, since the mechanisms behind these symptoms are considered to have different mechanisms and are treated differently.

Patients who fail to recover from sciatic pain are at risk to develop chronic pain syndromes, which emphasizes the importance of identifying factors that can predict the outcome, both regarding short- and long-term results. Therefore, possible predictive factors for the surgical outcome have been studied, factor as age [10], sex [11], duration of leg pain [12], time to surgery [13], working status [14], type and level of disc herniation $[4,15,16]$ and psychosocial factors $[17,18]$.

The aim of the present study was to investigate the longterm result after lumbar disc herniation surgery and to investigate if any demographics such as psychological, social or physiological factors could predict the surgical outcome. The primary outcomes were neurological evaluation of surgical outcome at 2-year follow-up and the patients satisfaction with treatment at 2-year and also at a longer follow-up, 5-10 years after surgery. The secondary outcomes at 2-year follow-up were improvement of leg and back pain, working capacity and the need for analgesics or sleeping pills.

\section{Materials and methods}

\section{Patients}

Between September 1996 and March 2002, one hundred and eighty-three consecutive patients surgically treated for a CT or MRI-verified one-level disc herniation on L4-L5 or L5-S1 level that correlated with the patients' symptoms were identified.

Patients with previous surgery on the herniated disc segment or with other spinal disorders were excluded and out of the initially identified 183 patients, 171 patients were included in the study. The study population had a mean age of $39 \pm 11$ years and $76(44 \%)$ of the patients were women.
Seventy-seven $(45 \%)$ of the patients underwent surgery at the L4-L5 level and 94 (55\%) at the L5-S1 level.

One hundred fifty-four $(90 \%)$ of the patients completed the 2-year follow-up and $140(81 \%)$ of the patients completed the long-term follow-up. The mean long-term follow-up time was $7.3 \pm 1.0(5.1-9.3)$ years.

The Regional Ethical Review Board approved the study and all patients gave their informed consent for inclusion.

\section{Surgical procedure}

A midline approach was used to dissect the paravertebral muscles down to the laminae and the interlaminar ligaments were resected. A partial laminotomy was performed when necessary. Herniated disc material and loose fragments from the disc was removed to decompress the affected neural structures. The surgery was performed with or without microscope due to the surgeons' preference. Six different spine surgeons performed the surgery at one hospital.

Baseline data and questionnaires

Preoperative questionnaires were used to collect information about baseline data (gender, age, smoking habits, level of surgery and analgesics consumption). The employment status and time to sick leave of the patients was recorded preoperatively, 2- and 5-10 (mean 7.3) years, postoperatively. The degree of leg and back pain, depression and disability was assessed at baseline and at both follow-up time-points using the Visual Analogue Scale (VAS), Zung Depression Scale (ZDS) and the Oswestry Disability Index (ODI). Leg and back pain was recorded with three VASs ranging from 0 to 100 , representing "pain when as worst", "pain when as least" and "pain right now". The mean value of the three scales was recorded as "VAS leg pain" and "VAS back pain".

ZDS and ODI are both validated questionnaires. The ZDS is a 20-item ordinal scale instrument with four response alternatives, giving a total score ranging from 20 to 80. A score of 55 or higher indicate depression [19]. The ODI describes back-related disability with a combination of physical and social restrictions. It contains 10 questions covering different dimensions of daily living. The sum can reach from $0 \%$, representing no disability, to $100 \%$, the worse possible disability $[20,21]$.

At the long-term follow-up, questionnaires were sent by mail, and if the patient did not respond, up to two reminders were sent by mail after telephone contact.

\section{Primary outcomes}

An independent observer, a neurologist, examined the patients, at the hospital, at 2-year follow-up and assessed 
the outcome based on Macnab classification of postoperative outcome (objective outcome) [22] (Fig. 1).

Patients' rated their satisfaction with treatment (satisfied, partly or not satisfied) at both follow-ups (subjective outcome).

\section{Secondary outcomes}

At the 2-year follow-up, the following variables were the secondary outcomes (answer alternatives within brackets):

- change in leg pain (improved or no improvement/ worse),

- change in back pain (improved or no improvement/ worse),

- working capacity (Full, Minor limitations, Only parttime, No capacity),

- analgesics (>1 day, 1/day, Rarely, None),

- sleeping pills (regular intake: yes or no)

\section{Predictors}

The potential predictors used in this study were gender, age, smoking habits, level of disc hernia, use of analgesics, time on sick leave, duration of leg pain, baseline leg and back pain, ZDS and ODI.

\section{Statistical analysis}

The primary outcome variables patient satisfaction and Macnab classification were dichotomized in the analyses. Patients' satisfaction was categorized as satisfied versus partly/not satisfied and Macnab classification was categorized as excellent/good versus poor/fair. Potential relationships with predictors were analyzed by using Chi-square test (categorical predictors), $t$ test (age as a predictor) or Mann-Whitney $U$ test. For multivariate analyses, logistic regression was used and all predictors that showed a potential influence in the bivariate analyses were included, i.e. predictors that showed a $p$ value lower than 0.20. Furthermore, in an explorative manner, the logistic regression models were also analyzed with a forward (likelihood ratio) stepwise selection procedure, aiming at finding the most influential predictor. Due to the explorative nature of the analyses and the large number of tests performed, low $p$ values should be regarded as interesting findings rather than conclusive evidence and should be followed up in confirmative studies.

\section{Results}

Baseline data and new surgery

All patients filled in questionnaires preoperatively with baseline data and information about leg and back pain, employment status, time to sick leave, depression and disability, presented in Table 1.

During the follow-up period 2 patients died and 16 patients had undergone at least one new lumbar spine operation. The most frequent new operation was recurrent disc herniation surgery performed at the same level ( 9 patients). Four patients had undergone fusion surgery due to chronic back pain and two patients were surgically treated because of a new disc herniation at another disc level. One of the patients was re-operated at another spine centre and no exact diagnosis could be retrieved.

Primary outcomes: objective outcome and patients' satisfaction

The independent observer (neurologist) reported excellent/ good results for 102/152 (67\%) of the patients and fair/poor results for $50 / 152(33 \%)$ of the patients at the 2-year follow-up (Table 2).

At the 2-year follow-up, $67 \%$ of the patients were satisfied, $28 \%$ were partly satisfied and 5\% not satisfied with surgical treatment. At the long-term follow-up $72 \%$ were satisfied, 24\% partly satisfied and 4\% not satisfied (Table 2).

Predictive factors for primary outcome: objective outcome

Preoperative short duration ( $<6$ months) of leg pain was found to be a predictive factor for objective good result $(p=0.039)$. In the group of patients with preoperative duration of leg pain less than 6 month, $78 \%$ were assessed as excellent/good at the 2-year follow-up compared to $62 \%$ for patients with duration between 6 and 12 months and $58 \%$ in the group with preoperative duration of leg pain exceeding
Fig. 1 Macnab classification of postoperative outcome

\begin{tabular}{|l|}
\hline Excellent; No pain. No restriction of activity. \\
\hline $\begin{array}{l}\text { Good; Occasional back or leg pain of sufficient severity to interfere with the patient's ability } \\
\text { to do his normal work or his capacity to enjoy himself in his leisure hours. }\end{array}$ \\
\hline $\begin{array}{l}\text { Fair; Improved functional capacity, but handicapped by intermittent pain of severity to curtail } \\
\text { or modify work or leisure activities. }\end{array}$ \\
\hline $\begin{array}{l}\text { Poor; No improvement or insufficient improvement to enable increase in activities. Further } \\
\text { operative intervention required. }\end{array}$
\end{tabular}

Excellent; No pain. No restriction of activity.

Good; Occasional back or leg pain of sufficient severity to interfere with the patient's ability to do his normal work or his capacity to enjoy himself in his leisure hours.

Fair; Improved functional capacity, but handicapped by intermittent pain of severity to curtail or modify work or leisure activities.

operative intervention required. 
Table 1 Baseline data of included patients

\begin{tabular}{|c|c|}
\hline \multicolumn{2}{|l|}{ Baseline data $(N=171)$} \\
\hline \multicolumn{2}{|l|}{ Gender $(\%)$} \\
\hline Female & $76(44)$ \\
\hline Male & $95(56)$ \\
\hline \multicolumn{2}{|l|}{ Age } \\
\hline Mean $\pm \mathrm{SD}$ & $39 \pm 11$ \\
\hline Smokers $(\%)$ & $45(27)$ \\
\hline \multicolumn{2}{|l|}{ Surgical level (\%) } \\
\hline L4-L5 & $77(45)$ \\
\hline L5-S1 & $94(55)$ \\
\hline \multicolumn{2}{|l|}{ VAS leg pain } \\
\hline Mean \pm SD & $59 \pm 19$ \\
\hline \multicolumn{2}{|l|}{ VAS back pain } \\
\hline Mean $\pm \mathrm{SD}$ & $50 \pm 23$ \\
\hline \multicolumn{2}{|l|}{ Analgesics $(\%)$} \\
\hline$>1 /$ day & $92(55)$ \\
\hline 1/day & $22(13)$ \\
\hline Rarely & $34(20)$ \\
\hline None & $20(12)$ \\
\hline \multicolumn{2}{|l|}{ Employment status (\%) } \\
\hline Employed & $123(75)$ \\
\hline Apply for job & $15(9)$ \\
\hline Disability pension (because of back pain) & $3(2)$ \\
\hline Disability pension (other reason) & $4(2.5)$ \\
\hline National basic (old age) pension & $4(2.5)$ \\
\hline Student & $15(9)$ \\
\hline \multicolumn{2}{|l|}{ Length of sick leave (months) } \\
\hline Mean $\pm \mathrm{SD}$ & $4.7 \pm 8.9$ \\
\hline \multicolumn{2}{|l|}{ Zung Depression Scale (20-80) } \\
\hline Mean (range) & $43(46)$ \\
\hline \multicolumn{2}{|l|}{ Oswestry Disability Index (0-100) } \\
\hline Mean (range) & $53(90)$ \\
\hline
\end{tabular}

12 months (Table 3). Further, patients with short time of sick leave ( $<2$ months) preoperatively were assessed to have an excellent/good result more frequent than patients with longer sick leave time $(p=0.001)$. For example, patients with a sick leave time $<2$ months were reported to have an excellent/good result in $82 \%$, compared with patients with sick leave period $>3$ months, where only $47 \%$ was reported as having an excellent/good result at the 2-year follow-up (Table 3). Additionally, a higher analgesics consumption $(p=0.022)$ and a somewhat higher mean age $(p=0.028)$ were seen in the group with excellent/good result (Table 3 ).

Predictive factors for primary outcome:

patients' satisfaction

Patients' degree of satisfaction with treatment was related to the time on sick leave preoperatively at both follow-up time-points. A short time of sick leave preoperatively, $<2$ months, predicted for a higher degree of satisfaction at both the 2- and 5-10-year follow-up ( $p=0.015$ and $p=0.028$, respectively). Among patients with a sick leave time lower than 2 months, $78 \%$ were satisfied at 2 -year follow-up (84\% at long-term follow-up) compared to patients who had been on a sick leave for at least 3 months were $52 \%$ were satisfied at 2-year follow-up (60\% at longterm follow-up). At long-term follow-up, the preoperative duration of leg pain was a predictor for satisfaction, i.e. duration less than 6 months correlated with a higher degree of satisfaction $(p=0.019)$ (Table 4$)$.

\section{Secondary outcomes and predictors}

Regarding leg pain (VAS) $88 \%$ of the patients reported an improvement, $12 \%$ no improvement/worse. Patients with improved leg pain had higher VAS leg pain at baseline $(60$ vs. 47) $p=0.008$. Patients with a VAS leg pain below the median (58), reported an improvement in $80 \%$ of all cases among patient who started with a leg pain higher than the median (worse pain) 96\% reported an improvement. Further, improved leg pain was related to analgesics, $94 \%$ of patients taking analgesics reported an improvement compared to $76 \%$ among patients taking no analgesics $(p=0.002)$. Improved leg pain was also related to sick leave. Among patients with a sick leave $<2$ months, $97 \%$ reported an improvement in leg pain. Among patients with sick leave between 2 and 3 months or longer the corresponding figures were 88 and $78 \%$, respectively. Finally, improved leg pain was also related to ODI. Patients with improved leg pain had a mean of 52 ODI compared to 42 in the other group (no improvement/worse) $p=0.040$.

Regarding back pain, $77 \%$ of the patients reported an improvement, $23 \%$ no improvement/worse. Patients with improved back pain had higher VAS back pain at baseline (53 vs. 36) $p=0.001$. Further, improved back pain was also related to ZDS. Patients with improved back pain had a mean of 42 ZDS compared to 39 in the other group (no improvement/worse) $p=0.045$. Finally, improved back pain was also related to ODI. Patients with improved back pain had a mean of 52 ODI compared to 44 in the other group (no improvement/worse) $p=0.040$.

Two-year after surgery 53\% reported full working capacity, $20 \%$ working capacity with only minor limitations, while $16 \%$ only could work part-time and $11 \%$ were not able to work at all. The working capacity was related to duration of leg pain. Among patients with duration shorter than 6 months, $67 \%$ reported full working capacity, while the corresponding figures were 42 and $43 \%$ among patients with duration of $6-12$ or longer than 12 months, respectively, $p=0.014$. The working capacity was also related to time on sick leave. Among patients with sick leave 
Table 2 Result at 2-year- and long-term follow-up for primary outcome parameters, VAS leg and back pain, Zung Depression Scale, Employment status, Oswestry Disability Index and number of patients on sick leave

\begin{tabular}{|c|c|c|c|c|}
\hline & $N$ & 2-year follow-up & $N$ & $\begin{array}{l}\text { Long-term follow-up } \\
\text { (mean } 7.3 \pm 1.0 \text { years) }\end{array}$ \\
\hline Patients satisfaction $(\%)$ & 148 & & 140 & \\
\hline Satisfied & & $99(67)$ & & $101(72)$ \\
\hline Partly satisfied & & $41(28)$ & & $33(24)$ \\
\hline Not satisfied & & $8(5)$ & & $6(4)$ \\
\hline Independent observer (\%) & 152 & & & \\
\hline Excellent & & $45(30)$ & & \\
\hline Good & & $57(37)$ & & \\
\hline Fair & & $40(26)$ & & \\
\hline Poor & & $10(7)$ & & \\
\hline VAS leg pain & 143 & & 140 & \\
\hline Mean $\pm \mathrm{SD}$ & & $24 \pm 24$ & & $17 \pm 22$ \\
\hline VAS back pain & 145 & & 140 & \\
\hline Mean \pm SD & & $26 \pm 24$ & & $18 \pm 19$ \\
\hline Employment status (\%) & 145 & & 135 & \\
\hline Employed & & $115(80)$ & & $96(71)$ \\
\hline Apply for job & & $5(3.5)$ & & $7(5)$ \\
\hline Disability pension (because of back pain) & & $5(3.5)$ & & $13(10)$ \\
\hline Disability pension (other reason) & & $6(4)$ & & $7(5)$ \\
\hline National basic (old age) pension & & $6(4)$ & & $10(7)$ \\
\hline Student & & $7(5)$ & & $2(2)$ \\
\hline Zung Depression Scale & 138 & & 138 & \\
\hline Mean (range) & & $36(44)$ & & $34(61)$ \\
\hline Oswestry Disability Index & 141 & & 137 & \\
\hline Mean (range) & & $20(78)$ & & $16(68)$ \\
\hline Sick leave $(\%)$ & 145 & & 134 & \\
\hline Yes & & $9(6)$ & & $12(9)$ \\
\hline No & & $136(94)$ & & $122(91)$ \\
\hline
\end{tabular}

$<2$ months, $69 \%$ reported full working capacity, compared to $62 \%$ for patients with sick leave between 2 and 3 months and $23 \%$ for patients with longer sick leave, $p<0.001$.

Considering analgesics, at 2-year follow-up, $4 \%$ of the patients consumes analgesics more than once a day, $10 \%$ of the patients once a day, $38 \%$ rarely and $48 \%$ none. The consumption of analgesics was related to baseline leg pain. Among patients consuming analgesics more than once a day the mean VAS leg pain was 77 at baseline, for patients with a once daily consumption the mean baseline for VAS leg pain was 63 , for patients with a rare consumption mean baseline VAS leg pain was 60 and for patients with no consumption the mean VAS leg pain was 55 at baseline, $p=0.046$.

Analgesics consumption was also related to time on sick leave. Among patients with a sick leave shorter than 2 months $12 \%$ used analgesics at least once daily, the corresponding figures was 7 and $27 \%$ for patients with a sick leave of 2-3 months and longer, respectively, $p=0.002$.
The last secondary outcome was sleeping pills, where $6 \%$ reported regular consumption at 2-year follow-up. The use of sleeping pills was related to time on sick leave. Among patients with a sick leave shorter than 2 months, $3 \%$ used sleeping pills regularly, the corresponding figures was 2 and $18 \%$ for patients with a sick leave of 2-3 months and longer, respectively, $p=0.008$. Patients with a regular consumption of sleeping pills also had higher mean baseline values for ZDS (mean $=44)$ and ODI $($ mean $=66)$ than patients with no regular consumption (ZDS mean $=42$, ODI mean $=52$ ), $p=0.020$ and 0.007 .

A summary of bivariate relationships between outcomes and predictors is found in Table 5 .

Multivariate analyses and the most influential predictors

There was multicollinearity, i.e. relationship between the predictors. For instance, the predictor months of sick leave 
Table 3 Baseline predictors for excellent/good objective outcome at 2-year follow-up ( $p$ values above 0.2 are noted ns)

\begin{tabular}{|c|c|c|c|}
\hline \multirow[t]{2}{*}{ Predictors } & \multicolumn{3}{|l|}{2 year follow-up } \\
\hline & Excellent/good & Poor/fair & $p$ value \\
\hline \multicolumn{4}{|l|}{ Gender (\%) } \\
\hline Female $(n=68)$ & 65 & 35 & \\
\hline Male $(n=84)$ & 69 & 31 & ns \\
\hline Age & $n=102$ & $n=50$ & \\
\hline Mean \pm SD & $42 \pm 11$ & $38 \pm 11$ & 0.028 \\
\hline \multicolumn{4}{|l|}{ Smokers (\%) } \\
\hline Yes $(n=38)$ & 68 & 32 & \\
\hline No $(n=113)$ & 67 & 33 & ns \\
\hline \multicolumn{4}{|l|}{ Surgical level (\%) } \\
\hline L4-L5 $(n=69)$ & 67 & 33 & \\
\hline L5-S1 $(n=83)$ & 67 & 33 & ns \\
\hline VAS leg pain & $n=96$ & $n=45$ & \\
\hline Mean & 71 & 70 & ns \\
\hline VAS back pain & $n=92$ & $n=46$ & \\
\hline Mean & 68 & 73 & ns \\
\hline \multicolumn{4}{|c|}{ Duration leg pain months (\%) } \\
\hline$<6(n=54)$ & 78 & 22 & \\
\hline $6-12(n=45)$ & 62 & 38 & \\
\hline$>12(n=38)$ & 58 & 42 & 0.039 \\
\hline Duration leg pain month & $n=92$ & $n=45$ & \\
\hline Mean & 64 & 80 & 0.021 \\
\hline \multicolumn{4}{|l|}{ Analgesics (\%) } \\
\hline$>1 /$ day $(n=81)$ & 73 & 27 & \\
\hline 1/day $(n=20)$ & 75 & 25 & \\
\hline Rarely $(n=30)$ & 43 & 57 & \\
\hline None $(n=18)$ & 72 & 33 & 0.022 \\
\hline \multicolumn{4}{|l|}{ Sick leave month (\%) } \\
\hline$<2(n=39)$ & 82 & 18 & \\
\hline $2-3(n=63)$ & 71 & 29 & \\
\hline$>3(n=43)$ & 47 & 53 & 0.001 \\
\hline Zung Depression Scale & $n=99$ & $n=49$ & \\
\hline Mean & 41 & 42 & ns \\
\hline Oswestry Disability Index & $n=100$ & $n=49$ & \\
\hline Mean & 53 & 52 & ns \\
\hline
\end{tabular}

was related to several of the other predictors: the use of analgesics, duration of leg pain, baseline leg and back pain and ODI. Relationships between predictors are illustrated in Table 6.

The multivariate analyses for the objective outcome showed no significant predictors when using the full model of potential predictors. The forward stepwise regression model selected time on of sick leave as the most influential predictor $(p=0.014)$ and age as the second predictor $(p=0.047)$.

Regarding patient satisfaction at 2-year follow-up, the full model showed no significant predictors, but the stepwise regression model selected time of sick leave as the only predictor $(p=0.017)$. At long-term follow-up, no significant predictors of patient satisfaction were found in the multivariate analysis.

For improvement in leg pain the only significant predictor among all potential predictors was baseline VAS leg pain $(p=0.039)$. Baseline VAS leg pain was also the first and only predictor selected by the stepwise procedure. Regarding improvement in VAS back pain, ZDS was the only significant predictor in both the full model $(p=0.049)$ and the stepwise model.

The time on sick leave was the only significant predictor ( $p=0.007)$, of working capacity, in both full model and stepwise model. In the same manner, the time on sick leave was the only significant predictor $(p=0.002)$ for post surgery use of analgesics. Finally, regarding the use of sleeping pills, the most influential predictor was time on sick leave followed by level of disc hernia and age. In summary, the time on sick leave is an important predictor for most of the outcomes; a summary of how different times on sick leave change the different outcomes is given in Table 7.

\section{Discussion}

In the present study, about $70 \%$ of the patients reported satisfaction with the surgical result at both the 2- and 5-10year follow-ups. The patient based results at the 2-year mark were in agreement with the result reported by the independent observer at the same time point. Previously, good short-term outcome after lumbar disc herniation surgery have been reported in up to $90 \%$ of the patients [3, $4,6,9]$. However, in the few previous studies with a follow-up period exceeding 1 year, the results obtained are in agreement with the result in the current study with about $2 / 3$ of the patients reporting good outcome.

The length of preoperative sick leave was identified as the most influential predictive factor both for objective outcome and subjective outcome and for several of the secondary outcomes as well. Among patients with a sick leave period shorter than 2 months the proportion of satisfactory outcome was around $80 \%$ according to both the assessment made by neurologist and the patients. Among patients with the longest sick leave ( $>3$ months), the corresponding figures was around 50\%. Furthermore, full working capacity was three times more common among patients with the shortest sick leave ( $<2$ months) compared to patients with the longest sick leave period ( $>3$ months) and the need for analgesics was twice as high in the latter group compared to the former. Finally, the chance of an improved leg pain was higher (97 vs. 78\%) in the group with shortest sick leave. We believe that these differences 
Table 4 Baseline predictors of patients' satisfaction at 2-year- and long-term follow-ups ( $p$ values above 0.2 are noted ns)

\begin{tabular}{|c|c|c|c|c|c|c|}
\hline \multirow[t]{2}{*}{ Predictors } & \multicolumn{3}{|c|}{ 2-year follow-up } & \multicolumn{3}{|c|}{ Long-term follow-up } \\
\hline & Yes & Partly/no & $p$ value & Yes & Partly/no & $p$ value \\
\hline \multicolumn{7}{|l|}{ Gender $(\%)$} \\
\hline Female $\left(n_{1}=67, n_{2}=67\right)$ & 64 & 36 & & 67 & 33 & \\
\hline Male $\left(n_{1}=81, n_{2}=74\right)$ & 69 & 31 & ns & 76 & 24 & ns \\
\hline Age & $n=99$ & $n=49$ & & $n=101$ & $n=40$ & \\
\hline Mean \pm SD & $40 \pm 11$ & $40 \pm 10$ & ns & $39 \pm 11$ & $39 \pm 11$ & ns \\
\hline \multicolumn{7}{|l|}{ Smokers $(\%)$} \\
\hline Yes $\left(n_{1}=37, n_{2}=33\right)$ & 68 & 32 & & 64 & 36 & \\
\hline No $\left(n_{1}=110, n_{2}=108\right)$ & 67 & 33 & ns & 74 & 26 & ns \\
\hline \multicolumn{7}{|l|}{ Surgical level (\%) } \\
\hline L4-L5 $\left(n_{1}=66, n_{2}=66\right)$ & 65 & 35 & & 68 & 32 & \\
\hline L5-S1 $\left(n_{1}=82, n_{2}=75\right)$ & 68 & 32 & ns & 75 & 25 & ns \\
\hline VAS leg pain & $n=91$ & $n=46$ & & $n=95$ & $n=39$ & \\
\hline Mean & 57 & 62 & ns & 58 & 59 & ns \\
\hline VAS back pain & $n=89$ & $n=46$ & & $n=93$ & $n=37$ & \\
\hline Mean & 47 & 54 & ns & 47 & 56 & ns \\
\hline \multicolumn{7}{|l|}{ Duration leg pain months (\%) } \\
\hline$<6\left(n_{1}=55, n_{2}=54\right)$ & 66 & 34 & & 82 & 18 & \\
\hline $6-12\left(n_{1}=44, n_{2}=40\right)$ & 68 & 32 & & 65 & 35 & \\
\hline$>12\left(n_{1}=35, n_{2}=34\right)$ & 63 & 37 & ns & 59 & 41 & 0.019 \\
\hline \multicolumn{7}{|l|}{ Analgesics (\%) } \\
\hline$>1 /$ day $\left(n_{1}=80, n_{2}=74\right)$ & 72 & 28 & & 77 & 23 & \\
\hline $1 /$ day $\left(n_{1}=19, n_{2}=16\right)$ & 63 & 37 & & 75 & 25 & \\
\hline Rarely $\left(n_{1}=30, n_{2}=28\right)$ & 50 & 50 & & 54 & 46 & \\
\hline None $\left(n_{1}=16, n_{2}=20\right)$ & 69 & 31 & $\mathrm{~ns}$ & 70 & 30 & $\mathrm{~ns}$ \\
\hline \multicolumn{7}{|l|}{ Sick leave month $(\%)$} \\
\hline$<2\left(n_{1}=37, n_{2}=37\right)$ & 78 & 22 & & 84 & 22 & \\
\hline $2-3\left(n_{1}=62, n_{2}=61\right)$ & 68 & 32 & & 69 & 32 & \\
\hline$>3\left(n_{1}=42, n_{2}=38\right)$ & 52 & 48 & 0.015 & 60 & 48 & 0.028 \\
\hline Zung depression scale & $n=95$ & $n=49$ & & $n=97$ & $n=40$ & \\
\hline Mean & 42 & 42 & ns & 42 & 44 & ns \\
\hline Oswestry Disability Index & $n=97$ & $n=48$ & & $n=99$ & $n=40$ & \\
\hline Mean & 54 & 51 & ns & 53 & 52 & ns \\
\hline
\end{tabular}

are clinically relevant and important from a patient perspective. Thus, the predictor time on sick leave is not only statistically significant but also a clinically relevant predictor. Patients with a long sick leave time preoperatively were found to have a less favourable outcome, also in a previous study [23]. In a recent study of work return after disc herniation surgery all the listed factors including long preoperative sick leave were demonstrated to be predictors for work return for patients after disc herniation surgery [24].

We found multicollinearity between the potential predictors, i.e. that the potential predictors were interrelated. A statistical consequence of this is that a multivariate regression model may give non-significant results even if several of the factors are important and significant in bivariate analyses. For instance, time on sick leave and duration of leg pain may both be important predictors, but since these variables are correlated a regression model may give non-significant results for one or both of the predictors. As a matter of fact, the predictor time on sick leave is actually related to several of the other variables; duration of leg pain, baseline pain in leg and back, preoperative use of analgesics and ODI. In several of the stepwise regression models, time on sick leave was selected first. The fact that other predictors were not selected does not mean that they are unimportant but they could be omitted just because part of the information they contain already is accounted for by time on sick leave already included in the model. Time on 
sick leave should be regarded as a summary variable containing a lot of information (several of the other predictors and possibly also other predictors not included in the study) - a kind of index for the patient situation, which may reflect how pronounced the health problem is. In short, time on sick leave should be regarded as a predictor and not as an explaining factor, i.e. we cannot claim causality between time on sick leave and outcome. The aim with this study was to find potential predictors, for being able to study causality and finding an explaining model a larger study would be needed.

Longstanding preoperative leg pain have been suggested to be a risk for the development of chronic pain and thereby a predictor of bad outcome $[1,12,25] . \mathrm{Ng}$ et al. found that patients with sciatica for more than

Table 5 Summary of significant predictors for primary and secondary outcomes found in the bivariate analyzes

\begin{tabular}{|c|c|}
\hline Outcomes & Relations \\
\hline \multicolumn{2}{|l|}{ Primary outcome } \\
\hline $\begin{array}{l}\text { Objective outcome at } 2 \text { - } \\
\text { year follow-up }\end{array}$ & $\begin{array}{l}\text { Significantly related to: age, duration of } \\
\text { leg pain, sick leave, analgesics }\end{array}$ \\
\hline $\begin{array}{l}\text { Patients' satisfaction at } \\
\text { 2-year follow-up }\end{array}$ & Sick leave \\
\hline $\begin{array}{l}\text { Patients' satisfaction at } \\
\text { long-term follow-up }\end{array}$ & Duration of leg pain, sick leave \\
\hline \multicolumn{2}{|l|}{ Secondary outcome } \\
\hline Improved leg pain & $\begin{array}{l}\text { Significantly related to: baseline leg } \\
\text { pain, analgesics, sick leave, ODI }\end{array}$ \\
\hline Improved back pain & Baseline back pain, ZDS, ODI \\
\hline Working capacity & Duration of leg pain, sick leave \\
\hline Analgesics & Baseline leg pain, sick leave \\
\hline Sleeping pills & Sick leave, ZDS, ODI \\
\hline
\end{tabular}

12 months have a less favourable outcome. In the present study, duration of leg pain for less than 6 months were related to good/excellent objective outcome at 2-year and good/excellent subjective outcome at the long-term follow-up.

The influence of both sick leave time and leg pain duration on postoperative results indicate that surgery for a lumbar disc herniation, when conservative treatment has failed, should be performed after a relatively short waiting time.

A herniation of a disc is a reflection of a disc degeneration process and may be associated with other types of spine problems such as chronic low back pain, instability or progressive deformity. In the present study, 16/171 (9\%) of the patients had undergone a new surgical procedure at the long-term follow-up and most commonly this was a new disc herniation at the same or another level. Similar numbers have been reported by Hakkinen et al. [6] who found that $10 \%$ of the patients had undergone a new spinal surgery within a 5-year period after surgery and 7\% was performed because of a new disc herniation. In the study of Atlas et al. [2], a higher frequency of additional spine surgery were found, $25 \%$ of the patients in this study had undergone at least one additional lumbar spine operation after 10 years. Since the frequency of performed spine surgery may be influenced of objective as well as subjective factors such as type of health system, surgical criteria's for interventions, etc., it is difficult to compare the numbers of repeated spine surgery presented in the different studies.

About $2 / 3$ of the patients in the present study were also included in a randomized study investigating the effect of ADCON-L on scar formation around nervous structures and clinical outcome [26]. No effects of ADCON-L were seen either on scar formation or outcome (objective or

Table 6 Relationships between the predictors used in the study

\begin{tabular}{|c|c|c|c|c|c|c|c|c|c|c|c|}
\hline & $\mathrm{G}$ & Age & $\mathrm{S}$ & SL & A & SLM & DLP & VLP & VBP & ZDS & ODI \\
\hline Gender (G) & & $\mathrm{T}$ & & & & & & * & & & \\
\hline Age & $\mathrm{T}$ & & & $*$ & & & & & & $*$ & $*$ \\
\hline Smoking (S) & & & & & & & & $*$ & & & \\
\hline Surgical level (SL) & & * & & & & & & & & $*$ & \\
\hline Analgesics (A) & & & & & & $* * *$ & $*$ & $* * *$ & $\mathrm{~T}$ & $* * *$ & $* * *$ \\
\hline Sick leave months (SLM) & & & & & $* * *$ & & $* * *$ & $*$ & $*$ & $\mathrm{~T}$ & $* * *$ \\
\hline Duration leg pain (DLP) & & & & & $*$ & $* * *$ & & & & & $*$ \\
\hline VAS leg pain (VLP) & $*$ & & $*$ & & $* * *$ & $*$ & & & $* * *$ & $* * *$ & $* * *$ \\
\hline VAS back pain (VBP) & & & & & $\mathrm{T}$ & $*$ & & $* * *$ & & $* * *$ & $* * *$ \\
\hline Zung Depression Scale (ZDS) & & $*$ & & $*$ & $* * *$ & $\mathrm{~T}$ & & $* * *$ & $* * *$ & & $* * *$ \\
\hline Oswestry Disability Index (ODI) & & $*$ & & & $* * *$ & $* * *$ & $*$ & $* * *$ & $* * *$ & $* * *$ & \\
\hline
\end{tabular}

$T$ tendency $(0.05<p<0.10), * 0.01<p<0.05, * * 0.001<p<0.01, * * * p<0.001$ 
Table 7 Summary of how lengths of sick leave affect the outcome at 2-year follow-up

\begin{tabular}{llll}
\hline Primary and secondary outcomes & \multicolumn{3}{c}{ Time on sick leave (months) } \\
\cline { 2 - 4 } & $<2$ & $2-3$ & $>3$ \\
\hline \% Excellent/Good (objective) & 82 & 71 & 47 \\
\% patients satisfied (subjective) & 78 & 68 & 52 \\
\% improved leg pain & 97 & 88 & 78 \\
\% full working capacity & 69 & 62 & 23 \\
\% need for analgesics & 38 & 42 & 80 \\
\% need for sleeping pills & 97 & 98 & 82 \\
\hline
\end{tabular}

subjective) why this factor was not included in the present study.

A limitation of the current study was that at the time of patient inclusion, there was a relatively long waiting time for surgery in our department and this may have influenced the result.

In summary, the long-term result after lumbar disc herniation surgery is satisfactory in around two out of three patients, while the remaining patients experience longlasting problems of some kind. Time on sick leave was found to be a clinically important predictor of the primary outcomes, with a potential of changing the probability of a satisfactory outcome (both objective and subjective) from around $50 \%$ (sick leave $>3$ months) to $80 \%$ (sick leave $<2$ months). Time on sick leave was also an important predictor for several of the secondary outcomes; e.g. working capacity and the need for analgesics. This highlight the importance of a well functioning health care organization, where time on the waiting list for clinical appointments as well as surgery do not delay the treatment to reach best possible result.

Acknowledgments The study was supported with grants from Marianne och Marcus Wallenberg's Foundation, ALF Västra Götaland, Gothenburg Medical association, The Swedish Society of Medicine and the The Neubergh Foundation.

\section{References}

1. Ng LC, Sell P (2004) Predictive value of the duration of sciatica for lumbar discectomy. A prospective cohort study. J Bone Joint Surg Br 86(4):546-549

2. Atlas SJ et al (2005) Long-term outcomes of surgical and nonsurgical management of sciatica secondary to a lumbar disc herniation: 10 year results from the Maine lumbar spine study. Spine 30(8):927-935

3. Asch HL et al (2002) Prospective multiple outcomes study of outpatient lumbar microdiscectomy: should 75 to $80 \%$ success rates be the norm? J Neurosurg 96(1 Suppl):34-44
4. Dewing CB et al (2008) The outcomes of lumbar microdiscectomy in a young, active population: correlation by herniation type and level. Spine 33(1):33-38

5. Ronnberg K et al (2007) Patients' satisfaction with provided care/ information and expectations on clinical outcome after lumbar disc herniation surgery. Spine (Phila Pa 1976) 32(2):256-261

6. Hakkinen A et al (2003) Does the outcome 2 months after lumbar disc surgery predict the outcome 12 months later? Disabil Rehabil 25(17):968-972

7. Loupasis GA et al (1999) Seven- to 20-year outcome of lumbar discectomy. Spine (Phila Pa 1976) 24(22):2313-2317

8. Weber H (1983) Lumbar disc herniation. A controlled, prospective study with ten years of observation. Spine (Phila Pa 1976) $8(2): 131-140$

9. Weinstein JN et al (2008) Surgical versus nonoperative treatment for lumbar disc herniation: four-year results for the Spine Patient Outcomes Research Trial (SPORT). Spine 33(25):2789-2800

10. Rothoerl RD et al (1998) Are there differences in the symptoms, signs and outcome after lumbar disc surgery in the elderly compared with younger patients? Br J Neurosurg 12(3):250-253

11. Peul WC et al (2008) Influence of gender and other prognostic factors on outcome of sciatica. Pain 138(1):180-191

12. Nygaard OP, Kloster R, Solberg T (2000) Duration of leg pain as a predictor of outcome after surgery for lumbar disc herniation: a prospective cohort study with 1-year follow up. J Neurosurg 92(2 Suppl):131-134

13. Rothoerl RD, Woertgen C, Brawanski A (2002) When should conservative treatment for lumbar disc herniation be ceased and surgery considered? Neurosurg Rev 25(3):162-165

14. Almeida DB et al (2007) Is preoperative occupation related to long-term pain in patients operated for lumbar disc herniation? Arq Neuropsiquiatr 65(3B):758-763

15. Halldin K et al (2009) Three-dimensional radiological classification of lumbar disc herniation in relation to surgical outcome. Int Orthop 33(3):725-730

16. Carragee EJ et al (2003) Clinical outcomes after lumbar discectomy for sciatica: the effects of fragment type and anular competence. J Bone Joint Surg Am 85-A(1):102-108

17. Kohlboeck $G$ et al (2004) Prognosis of multifactorial outcome in lumbar discectomy: a prospective longitudinal study investigating patients with disc prolapse. Clin J Pain 20(6):455-461

18. Junge A et al (1996) Predictors of bad and good outcome of lumbar spine surgery. A prospective clinical study with 2 years' follow up. Spine 21(9):1056-1064 (discussion 1064-1065)

19. Zung WW (1965) A self-rating depression scale. Arch Gen Psychiatry 12:63-70

20. Fairbank JC, Pynsent PB (2000) The Oswestry Disability Index. Spine 25(22):2940-2952 (discussion 2952)

21. Fairbank JC et al (1980) The Oswestry low back pain disability questionnaire. Physiotherapy 66(8):271-273

22. Macnab I (1973) Chapter 14. Pain and disability in degenerative disc disease. Clin Neurosurg 20:193-196

23. Nygaard OP, Romner B, Trumpy JH (1994) Duration of symptoms as a predictor of outcome after lumbar disc surgery. Acta Neurochir (Wien) 128(1-4):53-56

24. Kitze K et al (2008) Preoperative predictors for the return to work of herniated disc patients. Zentralbl Neurochir 69(1):7-13

25. Hurme M, Alaranta $H$ (1987) Factors predicting the result of surgery for lumbar intervertebral disc herniation. Spine 12(9):933-938

26. Ronnberg K et al (2008) Peridural scar and its relation to clinical outcome: a randomised study on surgically treated lumbar disc herniation patients. Eur Spine J 17(12):1714-1720 